\title{
Factors Affecting Optimal Titration Pressure of Continuous Positive Airway Pressure Device in Patients with Obstructive Sleep Apnea Syndrome
}

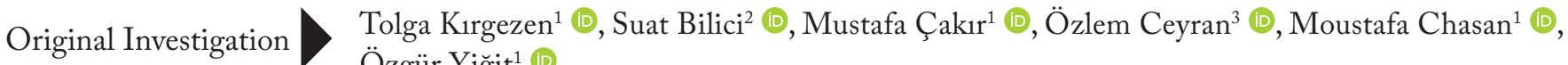 \\ Özgür Yiğit ${ }^{1}$ \\ ${ }^{1}$ Department of Otorhinolaryngology/Head and Neck Surgery, İstanbul Training and Research Hospital, İstanbul, Turkey \\ ${ }^{2}$ Department of Otorhinolaryngology/Head and Neck Surgery, Acıbadem University Atakent Hospital, İstanbul, Turkey \\ ${ }^{3}$ Department of Chest Diseases, İstanbul Training and Research Hospital, İstanbul, Turkey
}

Abstract

ORCID iDs of the authors: T.K. 0000-0003-1965-6408; S.B. 0000-0002-0165-9902 M.C. 0000-0002-1249-9334; ö.C. 0000-0002-3454-5055; M.C. 0000-0002-0996-889X; Ö.Y. 0000-0003-1731-3233.

Cite this article as: Kirgezen T, Bilici S, Çakır M, Ceyran Ö, Chasan M, Yiğit Ö. Factors Affecting Optimal Titration Pressure of Continuous Positive Airway Pressure Device in Patients with Obstructive Sleep Apnea Syndrome. Turk Arch Otorhinolaryngol 2020; 58(2):80-6.

\section{Corresponding Author:}

Tolga Kirgezen, tolgakirgezen@gmail.com

Received Date: 25.11 .2019

Accepted Date: 09.02 .2020

Content of this journal is licensed under a Creative Commons Attribution 4.0 International License. Available online at www.turkarchotolaryngol.net
Objective: To assess the effects of anatomical, clinical parameters, and pulmonary respiratory function on the therapeutic titration pressure of continuous positive airway pressure (CPAP) device in obstructive sleep apnea syndrome (OSAS).

Methods: The study comprised 41 OSAS patients whose optimum CPAP titration pressures were measured. Each patient underwent an otorhinolaryngologic and thoracic examination, and data was recorded for height, weight, body mass index, neckwaist circumferences, Mallampati classification, tonsillar hypertrophy, hypopharyngeal collapse, soft palate-tongue base obstruction scores, peak nasal inspiratory flow and acoustic rhinometry measures, and CPAP device therapeutic pressures. Forced vital capacity, forced expiratory volume, FEV1/FVC ratio and peak expiratory flow values were noted.

Results: Median CPAP optimal pressure cut-off value was determined as $9 \mathrm{mmH}_{2} \mathrm{O}$. Statistical analysis was made in two groups as CPAP titration optimal pressure $\leq 9$ and $>9 \mathrm{mmH}_{2} \mathrm{O}$. In the optimal pressure $>9$ group, neck and waist circumferences, hypopharyngeal collapse score, retropalatal and retrolingual lateral wall collapse scores were significantly higher $(\mathrm{p}<0.05)$. In multivariate and univariate model analysis, neck and waist circumferences, hypopharyngeal collapse score, retropalatal and retrolingual lateral wall collapse scores were observed to be significant in predicting high and low pressures in univariate model.

Conclusion: For the prediction of optimal CPAP titration pressure in OSAS treatment, wide neck and waist circumferences, high hypopharyngeal collapse score and retropalatal and retrolingual lateral wall collapse grades may be determinative.

Keywords: Continuous positive airway pressure, apnea hypopnea index, obstructive sleep apnea syndrome, sleep disorder, CPAP titration

\section{Introduction}

Obstructive sleep apnea is a clinical entity resulting from the partial or complete obstruction of air flow during sleep with repeating episodes. Epidemiological studies show that obstructive sleep apnea syndrome (OSAS) affects middle aged men and women by $4 \%$ and $2 \%$, respectively (1).

The continuous positive airway pressure (CPAP) device was first used in 1981 for the treatment of OSAS and is still being used successfully worldwide today in the treatment of patients with moderate to severe OSAS $(2,3)$. The aim of positive airway pressure (PAP) techniques is to maintain and open the upper respiratory tract during sleep, and thereby, to regulate the quality of respiration and sleep. Optimal pressure can be identified as the minimum positive pressure to eliminate incidents related to apnea, hypopnea, desaturation, snoring and respiration (4).

CPAP pressure values used in the treatment of sleep breathing disorders are determined by the results of repetitive titrations. These values depend on many anatomical and physiological variants in the upper and lower respiratory tract. Although it is maintained that the apnea hypopnea index (AHI)-also known as obstructive sleep apnea (OSA) severity-is one of the aforementioned variants, other factors that affect optimal pressure are not yet completely understood. However, it has been predicted that certain anthropometric and 
polysomnographic parameters contribute to the determination of optimal CPAP pressure (5).

Although CPAP treatment has been used successfully in most OSA patients, as yet the parameters predicting optimal pressure for CPAP have not been fully identified. In the literature, there is only a small number of studies evaluating the other factors that could be effective in the determination of optimal CPAP pressure.

The aim of this study is to evaluate the effects of anatomical, clinical parameters and the pulmonary respiratory capacity on the optimal therapeutic CPAP pressure induced by titration in OSAS patients.

\section{Methods}

This study comprises 41 patients who applied to our hospital's Otolaryngology and Chest Diseases Departments from December 2018 through November 2019 and were diagnosed with OSAS as the result of their medical stories, clinical findings and polysomnography (PSG), and whose optimum CPAP pressure values were determined using CPAP titration. An informed consent was taken from each patient in this study.

CPAP delivers a single, fixed pressure to the patient during the night. The optimal setting for the titration of CPAP was provided by an American Academy of Sleep Medicine (AASM) accredited sleep center or laboratory, with the titration protocol implemented by registered polysomnographic technologists. A review of the titration study (including pressure selection) was conducted by a board certified sleep specialist. Additionally, definitions, protocols, procedures, and indications for the diagnosis and management of OSA were provided, as specified in the AASM practice parameters for PSG (6).

For the prospective study, approval was obtained from the Ethical Commitee of Clinical Researches of İstanbul Training and Research Hospital (Approval Date: December 7, 2018; Approval Number: 1574). Along with their demographic and medical histories, the study patients were subject to a complete otorhinolaryngologic and thoracic examination, and data regarding height, weight, body mass index (BMI), neck and waist circumference, Mallampati classification, tonsillar hypertrophy, hypopharyngeal collapse score, soft palate and tongue base obstruction score, peak nasal inspiratory flow (PNIF) rate, pulmo-

\section{Main Points}

- Wide neck and waist circumferences, high hypopharyngeal collapse score and retropalatal and retrolingual lateral wall collapse grades were found as more determinative for the prediction of the optimal titration pressure for the CPAP device in the treatment of the OSAS patients.

- A positive correlation was observed between the optimal CPAP pressure and BMI, and the neck circumference and retrolingual lateral wall collapse scores.

- The lateral wall collapse in the retropalatal and retrolingual regions has more effects on the optimal CPAP device pressure than compared to anterior-posterior collapse. nary function tests and CPAP device therapeutic pressure values were documented.

Mallampati scoring (Grades I-II-III-IV) was applied for oropharynx. Depending on the narrowness grade, tonsils in fossa were graded as: 0, 1 for narrowness levels below 25\%, 2 for narrowness levels between $25 \%$ and 50\%, 3 for levels between $50 \%$ and $75 \%$ and 4 for levels above $75 \%$. Larynx-hypopharynx examinations were made by flexible endoscope and hypopharyngeal collapse was scored between grades 1 and 4 . Following the awake Muller's maneuver, which was conducted with a flexible videoendoscope, the observations were compared. The findings were described and scored using the VOTE classification system, which includes the following features: antero-posterior and lateral wall collapse degrees of retropalatal (soft palate) and retrolingual (base of tongue) regions (7).

Forced vital capacity (FVC), forced expiratory volume (FEV1), FEV1/FVC ratio and peak expiratory flow (PEF) values were noted. Values were measured by acoustic rhinometry, right and left internal isthmus cross sectional area (MCA1), and inferior concha cross sectional area (MCA2). PNIF values were noted. Nasal cavity was evaluated via a $0^{0}$ endoscope.

Patients with a history of upper and lower respiratory tract surgery and nasal diseases such as allergic rhinitis, nasal polyps, obstructing pathologies such as septal deviation, nasal valve problems and turbinate hypertrophies (patients with obstructing nasal pathologies were recruited for the study following their surgical treatment but before performing their CPAP titrations), but patients with other upper and lower respiratory tract problems, serious systematic and neurological illnesses were excluded from the study. An analysis was made of the data gathered from the examinations and measurements.

\section{Statistical Analysis}

In accordance with the descriptive statistics of data, average, standard deviation, lowest and highest median, frequency and ratio values were used. The Kolmogorov-Smirnov test was used to test the range of variations. The Mann-Whitney $U$ test was used for the analysis of quantitative independent data. The chi-square test was used for the analysis of qualitative independent data and Spearman's correlation analysis was used for correlation analysis. Degree of influence was analyzed using multivariant and univariant logistic regression. Analysis was made using the IBM Statistical Package for the Social Sciences software for Windows version 22.0 (IBM SPSS Corp.; Armonk, NY, USA).

\section{Results}

Data collected from the 41 patients included in the study were documented in Table 1 . Of the 41 patients, 14 were female (34.1\%) and 27 were male (65.9\%). The age average of the study group was 51.6 \pm 8.8 . The weight, height and BMI averages of the group were $96 \pm 14.5,169.2 \pm 11.1,33.7 \pm 4.8$, respectively. The CPAP optimal pressure average value was measured as $8.9 \pm 1.5$. Median CPAP optimal pressure cut-off value was determined as 
Kirgezen et al.

Table 1. Demographic data and parameters measured in all patients

\begin{tabular}{|c|c|c|c|c|c|}
\hline & & Min-Max & Median & $\mathrm{AV} . \pm \mathrm{SD}$ & $\mathrm{n} / \%$ \\
\hline Optimal CPAP pressure level & & $6.0-11.0$ & 9.0 & $8.9 \pm 1.5$ & \\
\hline Age & & $33.0-82.0$ & 53.0 & $51.6 \pm 8.8$ & \\
\hline \multirow[t]{2}{*}{ Gender } & Female & & & & $14 / 34.1 \%$ \\
\hline & Male & & & & $27 / 65.9 \%$ \\
\hline Weight & & $60.0-123.0$ & 99.0 & $96.1 \pm 14.5$ & \\
\hline Height & & 142.0-190.0 & 169.0 & $169.2 \pm 11.1$ & \\
\hline BMI & & $24.1-49.1$ & 33.2 & $33.7 \pm 4.8$ & \\
\hline Neck circ. & & $35.0-52.0$ & 44.0 & $43.7 \pm 3.9$ & \\
\hline Waist circ. & & $88.0-130.0$ & 111.0 & $109.4 \pm 10.1$ & \\
\hline AHI & & $3.2-93.5$ & 51.8 & $54.1 \pm 21.4$ & \\
\hline \multirow[t]{3}{*}{ Oropharynx narrowness } & II & & & & $14 / 34.1 \%$ \\
\hline & III & & & & $16 / 39.0 \%$ \\
\hline & IV & & & & $11 / 26.8 \%$ \\
\hline \multirow[t]{4}{*}{ Tonsil hypertrophy } & 0 & & & & $4 / 9.8 \%$ \\
\hline & $\mathrm{I}$ & & & & $22 / 53.7 \%$ \\
\hline & II & & & & $9 / 22.0 \%$ \\
\hline & III & & & & $6 / 14.6 \%$ \\
\hline \multirow[t]{3}{*}{ Hypopharyngeal collapse } & I & & & & $17 / 41.5 \%$ \\
\hline & II & & & & $17 / 41.5 \%$ \\
\hline & III & & & & $7 / 17.1 \%$ \\
\hline Anteroposterior retropalatal collapse & & $0.0-100.0$ & 25.0 & $37.6 \pm 29.2$ & \\
\hline Lateral to lateral retropalatal collapse & & $0.0-75.0$ & 25.0 & $28.0 \pm 24.5$ & \\
\hline Anteroposterior retrolingual collapse & & $0.0-50.0$ & 0.0 & $14.3 \pm 16.7$ & \\
\hline Lateral retrolingual collapse & & $0.0-50.0$ & 0.0 & $11.6 \pm 15.9$ & \\
\hline PNIF & & $40.0-140.0$ & 75.0 & $73.2 \pm 19.6$ & \\
\hline L.MCA1 & & $0.2-0.8$ & 0.6 & $0.6 \pm 0.2$ & \\
\hline L.MCA2 & & $0.2-1.6$ & 0.5 & $0.6 \pm 0.3$ & \\
\hline R.MCA1 & & $0.2-0.9$ & 0.6 & $0.5 \pm 0.2$ & \\
\hline R.MCA2 & & $0.2-1.0$ & 0.4 & $0.5 \pm 0.2$ & \\
\hline FVC & & $1.8-33.3$ & 3.6 & $5.0 \pm 6.6$ & \\
\hline FEV1 & & $0.9-5.0$ & 3.0 & $2.9 \pm 0.9$ & \\
\hline FEV1/FVC & & $44.0-100.0$ & 81.0 & $81.9 \pm 11.5$ & \\
\hline PEF & & $1.1-9.9$ & 5.7 & $5.6 \pm 1.9$ & \\
\hline
\end{tabular}

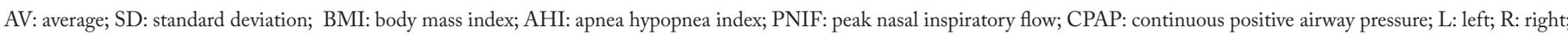
MCA: mean cross-sectional area in acoustic rhinometry; FVC: forced vital capacity; FEV: forced expiratory volume; PEF: peak expiratory flow; Min: minimum; Max: maximum

$9 \mathrm{mmH}_{2} \mathrm{O}$. Statistical analysis was made in two groups as CPAP titration optimal pressure $\leq 9$ and $>9 \mathrm{mmH}_{2} \mathrm{O}$.

The AHI score average of all the patients was $54.1 \pm 21.4$. In Mallampati score test, $34.1 \%$ of the patients were found to be grade 2, 39\% grade 3 and $26.8 \%$ grade 4 . In hypopharyngeal collapse scoring, 17 patients were grade 1 (41.5\%), 17 were grade 2 $(41.5 \%)$ and 7 were grade $3(17.1 \%)$. As a result of Muller's maneuver, the retropalatal anterior-posterior collapse score average was $37.6 \pm 29.2 \%$, retropalatal lateral wall collapse average was $28 \pm 24.5 \%$, retrolingual anterior-posterior collapse score average was $14.3 \pm 16.7$ and the retrolingual lateral wall collapse score average was $11.6 \pm 15.9$.
In patient groups with pressures $\leq 9$ and $>9$, no significant differences were found between age and gender, weight, height and $B M I$ values $(p>0.05)$. For the pressure $>9$ group, the neck and waist circumferences were significantly higher compared to the pressure $\leq 9$ group ( $p=0.004$ and 0,019 ; respectively). For the pressure $>9$ group, the hypopharynx collapse degree was significantly higher compared to the pressure $\leq 9$ group $(p=0.021)$. For the pressure $>9$ group, MCA2 value was significantly higher compared to the pressure $\leq 9$ group $(p=0.012)$ (Table 2).

Regarding the awake Muller's maneuver scores of patients, retrolingual lateral wall collapse and retropalatal lateral wall col- 
Table 2. Analysis of optimal pressure parameters in accordance with the pressure groups

\begin{tabular}{|c|c|c|c|c|c|c|}
\hline & & \multicolumn{2}{|c|}{ Optimal CPAP Pressure $\leq 9$} & \multicolumn{2}{|c|}{ Optimal CPAP Pressure $>9$} & \multirow[b]{2}{*}{$\mathrm{p}$} \\
\hline & & $\mathrm{AV} \pm \mathrm{SD} / \mathrm{n}-\%$ & Median & $\mathrm{AV} \pm \mathrm{SD} / \mathrm{n}-\%$ & Median & \\
\hline Age & & $53.2 \pm 10.2$ & 55.0 & $50.0 \pm 7.1$ & 52.0 & $0.219^{\mathrm{m}}$ \\
\hline \multirow[t]{2}{*}{ Gender } & Female & $9-42.9 \%$ & & $5-25.0 \%$ & & $0.228^{\mathrm{X}^{2}}$ \\
\hline & Male & $12-57.1 \%$ & & $15-75.0 \%$ & & \\
\hline Weight & & $92.4 \pm 15.5$ & 88.0 & $100.1 \pm 12.7$ & 100.0 & $0.114^{\mathrm{m}}$ \\
\hline Height & & $166.8 \pm 12.7$ & 168.0 & $171.8 \pm 8.7$ & 171.0 & $0.296^{\mathrm{m}}$ \\
\hline BMI & & $33.4 \pm 5.8$ & 31.2 & $33.9 \pm 3.7$ & 34.9 & $0.246^{\mathrm{m}}$ \\
\hline Neck circ. & & $41.9 \pm 4.0$ & 43.0 & $45.7 \pm 2.7$ & 46.0 & $0.004^{\mathrm{m}}$ \\
\hline Waist circ. & & $105.4 \pm 9.5$ & 102.0 & $113.7 \pm 9.1$ & 116.0 & $0.019^{\mathrm{m}}$ \\
\hline AHI & & $48.2 \pm 21.9$ & 51.8 & $60.4 \pm 19.5$ & 53.8 & $0.090^{\mathrm{m}}$ \\
\hline \multirow[t]{3}{*}{ Oropharynx narrowness } & II & $7-33.3 \%$ & & $7-35.0 \%$ & & $0.105^{\mathrm{X}^{2}}$ \\
\hline & III & $11-52.4 \%$ & & $5-25.0 \%$ & & \\
\hline & IV & $3-14.3 \%$ & & $8-40.0 \%$ & & \\
\hline \multirow[t]{4}{*}{ Tonsillar hypertrophy } & 0 & $2-9.5 \%$ & & $2-10.0 \%$ & & $0.687^{\mathrm{X}^{2}}$ \\
\hline & $\mathrm{I}$ & $13-61.9 \%$ & & $9-45.0 \%$ & & \\
\hline & II & $4-19.0 \%$ & & $5-25.0 \%$ & & \\
\hline & III & $2-9.5 \%$ & & $4-20.0 \%$ & & \\
\hline \multirow[t]{3}{*}{ Hypopharyngeal collapse } & I & $13-61.9 \%$ & & $4-20.0 \%$ & & $0.021^{\mathrm{X}^{2}}$ \\
\hline & II & $5-23.8 \%$ & & $12-60.0 \%$ & & \\
\hline & III & $3-14.3 \%$ & & $4-20.0 \%$ & & \\
\hline Anteroposterior retropalatal collapse & & $38.8 \pm 31.3$ & 25.0 & $36.3 \pm 27.5$ & 37.5 & $0.861^{\mathrm{m}}$ \\
\hline Lateral retropalatal collapse & & $20.2 \pm 18.7$ & 25.0 & $36.3 \pm 27.5$ & 50.0 & $0.046^{\mathrm{m}}$ \\
\hline Anteroposterior retrolingual collapse & & $15.5 \pm 16.7$ & 25.0 & $13.0 \pm 17.0$ & 0.0 & $0.603^{\mathrm{m}}$ \\
\hline Lateral retrolingual collapse & & $3.6 \pm 9.0$ & 0.0 & $20.0 \pm 17.4$ & 25.0 & $0.001^{\mathrm{m}}$ \\
\hline PNIF & & $71.2 \pm 23.3$ & 65.0 & $75.3 \pm 15.2$ & 80.0 & $0.222^{\mathrm{m}}$ \\
\hline Optimal CPAP Pressure & & $7.6 \pm 0.8$ & 8.0 & $10.3 \pm 0.5$ & 10.0 & $0.000^{\mathrm{m}}$ \\
\hline LMCA1 & & $0.5 \pm 0.2$ & 0.5 & $0.6 \pm 0.2$ & 0.6 & $0.619^{\mathrm{m}}$ \\
\hline LMCA2 & & $0.6 \pm 0.4$ & 0.5 & $0.6 \pm 0.2$ & 0.5 & $0.764^{\mathrm{m}}$ \\
\hline RMCA1 & & $0.6 \pm 0.2$ & 0.6 & $0.5 \pm 0.2$ & 0.5 & $0.186^{\mathrm{m}}$ \\
\hline RMCA2 & & $0.6 \pm 0.2$ & 0.6 & $0.4 \pm 0.2$ & 0.3 & $0.012^{\mathrm{m}}$ \\
\hline FVC & & $6.2 \pm 9.1$ & 3.5 & $3.8 \pm 0.9$ & 3.8 & $0.309^{\mathrm{m}}$ \\
\hline FEV1 & & $2.8 \pm 1.0$ & 2.8 & $3.0 \pm 0.7$ & 3.0 & $0.449^{\mathrm{m}}$ \\
\hline FEV1/FVC & & $82.9 \pm 12.2$ & 81.0 & $80.9 \pm 10.9$ & 80.5 & $0.539^{\mathrm{m}}$ \\
\hline PEF & & $5.4 \pm 2.0$ & 4.9 & $5.9 \pm 1.9$ & 6.2 & $0.206^{\mathrm{m}}$ \\
\hline
\end{tabular}

mMann-Whitney u test

$\mathrm{X}^{2}$ Chi-square test

AV: average; SD: standard deviation; BMI: body mass index; AHI: apnea hypopnea index; PNIF: peak nasal inspiratory flow; CPAP: continuous positive airway pressure; L: left; R: right; MCA: mean cross-sectional area in acoustic rhinometry; FVC: forced vital capacity; FEV: forced expiratory volume; PEF: peak expiratory flow

lapse value of the pressure $>9$ group was found to be significantly higher compared to the pressure $\leq 9$ group ( $\mathrm{p}=0.001$ and 0.046 , respectively).

With regard to the prediction of high and low pressures in the univariant model, the neck and waist circumferences, hypopharyngeal collapse score, retropalatal lateral wall collapse score and retrolingual lateral wall collapse score were found to be significantly effective ( $\mathrm{p}=0.006,0.012,0.043,0.041,0.003$; respectively) (Table 3).
With regard to the prediction of high and low pressures in multivariant model, the neck circumference and retrolingual lateral wall collapse scores were found to be significantly and independently effective ( $\mathrm{p}=0.011$ and 0.006 ; respectively) (Table 3 ).

As a result of the awake Muller's maneuver conducted using flexible endoscopy on both groups, retropalatal and retrolingual antero-posterior collapse scores, PNIF value, left MCA1 and MCA2 and right MCA1 values, FVC, FEV1, FEV1/FVC ratios and PEF values showed no significant differences ( $p>0.05)$. 
Kurgezen et al.

Table 3. Univariant and multivariant regression models for optimal pressure parameters

\begin{tabular}{l|c|c|c|c|c}
\hline & \multicolumn{3}{|c|}{ Univariant model } & \multicolumn{2}{c}{ Multivariant model } \\
\hline Neck circ. & Mean & 95\% Confidence interval & $\mathrm{p}^{*}$ & Mean & 95\% Confidence interval \\
\hline Waist circ. & 1.44 & $1.11-1.87$ & 0.006 & 1.48 & $1.09-2.00$ \\
\hline Hypopharyngeal collapse & 1.10 & $1.02-1.19$ & 0.012 & & 0.011 \\
\hline Retropalatal lateral collapse & 2.65 & $1.03-6.82$ & 0.043 & & \\
\hline Retrolingual lateral collapse & 1.03 & $1.00-1.06$ & 0.041 & & \\
\hline
\end{tabular}

*Logistic Regression

Table 4. Correlation of optimal pressure, AHI and other parameters

\begin{tabular}{|c|c|c|c|c|c|c|c|c|}
\hline & & AHI & Age & Weight & Height & BMI & Neck circ. & Waist circ. \\
\hline \multirow[t]{2}{*}{ Optimal CPAP Pressure } & $\mathrm{r}$ & 0.330 & -0.236 & 0.257 & -0.003 & 0.343 & 0.414 & 0.396 \\
\hline & $\mathrm{p}$ & $0.035^{*}$ & 0.137 & 0.105 & 0.983 & $0.028^{*}$ & $0.007^{*}$ & $0.010^{*}$ \\
\hline \multirow[t]{3}{*}{ AHI } & $\mathrm{r}$ & & -0.199 & 0.193 & 0.118 & 0.147 & 0.071 & 0.204 \\
\hline & $\mathrm{p}$ & & 0.212 & 0.228 & 0.464 & 0.359 & 0.657 & 0.201 \\
\hline & & $\begin{array}{c}\text { Retropalatal } \\
\text { anteroposterior }\end{array}$ & $\begin{array}{c}\text { Retropalatal } \\
\text { lateral }\end{array}$ & $\begin{array}{l}\text { Retrolingual } \\
\text { anteroposterior }\end{array}$ & $\begin{array}{l}\text { Retrolingual } \\
\text { lateral }\end{array}$ & PNIF & L. MCA1 & \\
\hline \multirow[t]{2}{*}{ Optimal CPAP Pressure } & $\mathrm{r}$ & -0.152 & 0.261 & -0.189 & 0.398 & 0.091 & 0.081 & \\
\hline & $\mathrm{p}$ & 0.342 & 0.099 & 0.237 & $0.010^{*}$ & 0.572 & 0.613 & \\
\hline \multirow[t]{3}{*}{$\mathrm{AHI}$} & $\mathrm{r}$ & 0.036 & 0.049 & 0.055 & -0.001 & 0.067 & -0.082 & \\
\hline & $\mathrm{p}$ & 0823 & 0.763 & 0.731 & 0.997 & 0.676 & 0.611 & \\
\hline & & MCA2 & R. MCA1 & MCA2 & $\mathrm{FVC}$ & FEV1 & $\mathrm{PEF}$ & \\
\hline \multirow[t]{2}{*}{ Optimal CPAP Pressure } & $\mathrm{r}$ & -0.144 & -0.100 & -0.264 & 0.195 & 0.125 & 0.175 & \\
\hline & $\mathrm{p}$ & 0.367 & 0.536 & 0.095 & 0.222 & 0.435 & 0.273 & \\
\hline \multirow[t]{2}{*}{$\mathrm{AHI}$} & $\mathrm{r}$ & -0.174 & -0.411 & -0.465 & 0.045 & -0.028 & 0.038 & \\
\hline & $\mathrm{p}$ & 0.277 & $0.008^{*}$ & $0.002^{*}$ & 0.781 & 0.862 & 0.812 & \\
\hline
\end{tabular}

*Spearman's Correlation

BMI: body mass index; AHI: apnea hypopnea index; PNIF: peak nasal inspiratory flow; CPAP: continuous positive airway pressure; L: left; R: right; MCA: mean cross-sectional area in acoustic rhinometry; FVC: forced vital capacity; FEV: forced expiratory volume; PEF: peak expiratory flow

In Spearman's correlation analysis a significant positive correlation was observed between the $\mathrm{AHI}, \mathrm{BMI}$, neck and waist circumferences and the retrolingual lateral wall collapse values. Conversely, a significant negative correlation was observed between the AHI value and right MCA1 and right MCA2 values. There was a positive correlation between optimal CPAP pressure and AHI value, BMI value, neck circumference, waist circumference, retrolingual lateral wall collapse score. There was, however, a negative correlation between AHI value and right MCA1, right MCA2 values (Table 4).

\section{Discussion}

We found that the thickness of neck and waist circumference, high hypopharyngeal collapse, retropalatal and retrolingual lateral wall collapse have a major effect on the increase of optimal CPAP pressure.

With reference to the determination of PAP optimal pressure, some studies in the literature concluded that AHI, BMI and neck circumference were the three most significant parameters $(8,9)$. In our study, an average neck circumference of $46 \mathrm{~cm}$ was significantly more common among the patients with above 9
$\mathrm{mmH}_{2} \mathrm{O}$ pressure compared to those below $9 \mathrm{~mm}(\mathrm{p}=0.004)$, while another study revealed that BMI was higher in patients with high optimal CPAP pressure (5). In a study conducted by Sforza et al. (10) no significant correlation was found between the AHI, BMI and optimal PAP pressure in 22 OSA cases where soft palate length and varied esophagus pressure predicted the optimal PAP pressure. However, in the study of Lin et al. (11), BMI and AHI were suggested as the two most important predictors of CPAP pressure in the eradication of obstructive sleep apneas.

In our study groups, the AHI score which many studies predict as the most significant factor in determining the PAP optimal pressure, did not indicate a significant difference; whereas, the results of the correlation analysis showed that there was a positive correlation between optimal CPAP pressure and AHI. This finding may be explained by the fact that all patients in our study were diagnosed with medium to severe OSA; the study group comprised patients to be treated with CPAP; and the majority of the patients had an AHI score above 50. Further, it was deemed that other non-considered parameters could have played a role in the results. 
In our study, we suggest the thickness of neck circumference as one of the major factors affecting optimal CPAP pressure. However, a study of 101 patients by Stradling et al. (12) proposes that neck circumference and OSA severity serve as independent variables in determining pressure. On the other hand, Oksenberg et al. (5) suggest that a direct proportion exists between the increase in optimal CPAP pressure and OSA severity.

In their study of OSA patients who have had bariatric surgery leading to rapid weight loss, Lankford et al. (13) observed varied CPAP pressures. In our study, however, it was noted that while the waist circumference of the patient group above $9 \mathrm{mmH}_{2} \mathrm{O}$ pressure was $113 \mathrm{~cm}$ in average, the average waist circumference of the patients in the other group was below $102 \mathrm{~cm}$, which can be considered as statistically significant $(\mathrm{p}=0.019)$. Although the waist circumference was expected to be higher in the patient group with higher BMI levels, in the present study BMI was not considered as a predictive parameter.

In our study the patients underwent anterior rhinoscopy, endoscopic nasal and nasopharyngeal examinations. At our clinic we do not perform CPAP titration in patients with various obstructive nasal problems, so initially the obstructing factors were eliminated. In our patients, the nasal obstructive pathologies were either absent or were treated prior to the CPAP titration procedure. Nasal tests were conducted with devices and acoustic rhinometry and PNIF tests were performed by the same author. Nasal obstruction may change titration pressure and if nasal obstruction increases the patient's adaptation to the CPAP device, the effectiveness of the device will decrease. As a result, in our study nasal pathologies are treated prior to CPAP titration. This method generally standardized the nasal passage opening for maximum positive effect of the device. In our study, nasal function tests were performed using acoustic rhinometry and PNIF.

It is well-known that an increase in the volume of adipose tissue between the pharynx and hypopharynx and the thickness in the muscular structure of pharynx play a role in narrowing the lateral circumference of the upper respiratory tract (14). In our study, all patients were scored in terms of retropalatal and retrolingual anteroposterior and lateral wall collapse by means of awake Muller's maneuver (forced inspiration of the patient with the mouth and nose covered), in which fiberoptic flexible endoscopy was used. In the patient group with a pressure value above $9 \mathrm{mmH}_{2} \mathrm{O}$, both retropalatal and retrolingual lateral wall collapse values were observed to be comparatively higher. Additionally, a direct proportion was noted between the increase in hypopharyngeal collapse score and CPAP optimal pressure. As the patients were subjectively evaluated prior to CPAP titration, these findings show that the awake Muller's maneuver could be of use in predicting optimal CPAP pressure. In our study it was also observed that the lateral wall collapse in the retropalatal and retrolingual regions was more effective compared to anterior-posterior collapse.

In the correlation analysis a positive correlation was observed between the optimal CPAP pressure and BMI, and the neck circumference and retrolingual lateral wall collapse scores. However, a negative correlation was observed between the AHI value and inferior turbinate cross section (acoustic rhinometry MCA2) as the nasal parameter.

An increase of the pulmonary volume leads to high blood pressure, the thickening of the pharynx wall, an increase in the cross section of upper respiratory tract and a decrease in upper respiratory tract resistance. Accordingly, upper respiratory tracts become harder to collapse. Due to the decrease in pulmonary volume in patients with high BMI and in supine position the pharyngeal wall collapses more easily (15-17). In our study, no significant difference was observed between the study groups in terms of FVC, FEV1, FEV1/FVC ratio or PEF, following pulmonary function tests. In addition, no significant correlation was noted between optimal CPAP pressure, AHI and respiratory capacity parameters. These findings demonstrate that anatomical variations relating to the upper respiratory tract are more important compared to the lower respiratory tract physiological parameters when determining optimal CPAP pressure.

Due to the vast number of parameters that require evaluation, it would be more determinative to observe larger groups of $\mathrm{pa}^{-}$ tients. Parameters, such as cephalometric analysis and the attendance of patients with lower optimal CPAP titration pressure value, could lead to more effective methods in the prediction of optimal CPAP pressure values.

\section{Conclusion}

In the prediction of optimal pressure values for the treatment of severe OSA patients with CPAP, the neck and waist circumference, high hypopharyngeal collapse score and retropalatal and retrolingual lateral wall collapse amount are key determinants. With regard to the patient group in our study, repetitive titration measurements may be reduced by employing simple pre-assessment practices and awake Muller's maneuver.

Ethics Committee Approval: Ethics committee approval was received for this study from the Ethical Commitee of Clinical Researches of İstanbul Training and Research Hospital (Approval Date: December 7, 2018; Approval Number: 1574).

Informed Consent: Written informed consent was obtained from the patients who participated in this study.

Peer-review: Externally peer-reviewed.

Author Contributions: Concept - T.K.; Design - T.K., S.B., Ö.Y.; Supervision - Ö.Y.; Data Collection and/or Processing - T.K., S.B., M.Ç., Ö.C., M.C.; Analysis and/or Interpretation - T.K., S.B., Ö.C.; Literature Search - T.K., M.Ç., Ö.C., M.C.; Writing - T.K., S.B.; Critical Reviews - Ö.Y.

Conflict of Interest: The authors have no conflicts of interest to declare.

Financial Disclosure: The authors declared that this study has received no financial support. 


\section{References}

1. Young T, Palta M, Dempsey J, Skatrud J, Weber S, Badr S. The occurrence of sleep-disordered breathing among middle-aged adults. N Engl J Med 1993; 328: 1230-5. [Crossref]

2. Sullivan CE, Issa F, Berthon-Jones M, Eves L. Reversal of obstructive sleep apnoea by continuous positive airway pressure applies through the nares. Lancet 1981; 1: 862-5. [Crossref]

3. Engleman HM, Kingshott RN, Wraith PK, Mackay TW, Deary IJ, Douglas NJ. Randomized placebo-controlled crossover trial of continuous positive airway pressure for mild sleep apnea/hypopnea syndrome. Am J Resp Crit Care Med 1999; 159: 46-7. [Crossref]

4. ATS statement. Indications and standards for use of nasal continuous positive airway pressure (CPAP) in sleep apnea syndromes. Am J Resp Crit Care Med 1994; 150: 1738-45. [Crossref]

5. Oksenberg A, Arons E, Froom P. Does the severity of obstructive sleep apnea predict patients requiring high continuous positive airway pressure? Laryngoscope 2006; 116: 951-5. [Crossref]

6. The American Academy of Sleep Medicine (AASM) Guidelines. (Access date: June 7th, 2020). https://aasm.org/clinical-resources/practice-standards/practice-guidelines/

7. Kezirian EJ, Hohenhorst W, de Vries N. Drug-induced sleep endoscopy: the VOTE classification. Eur Arch Otorhinolaryngol 2011; 268: 1233-6. [Crossref]

8. Miljeteig $\mathrm{H}$, Hoffstein V. Determinants of continuous positive airway pressure level for the treatment of obstructive sleep apnea. Am Rev Respir Dis 1993; 147: 1526-30. [Crossref]
9. Hoffstein V, Mateika S. Predicting nasal continuous positive pressure. Am Rev Respir Dis. 1993; 150: 486-8. [Crossref]

10. Sforza E, Krieger J, Bacon W, Petiau C, Zamagni M, Boudewijns A. Determinants of effective continuous positive airway pressure in obstructive sleep apnea. Role of respiratory effort. Am J Respir Crit Care Med 1995; 151: 1852-6. [Crossref]

11. Lin IF, Chuang ML, Liao YF, Chen NH, Li HY. Predicting effective continuous positive airway pressure in Taiwanese patients with obstructive sleep apnea syndrome. J Formos Med Assoc 2003; 102: 215-21.

12. Stradling JR, Hardinge M, Paxton J, Smith DM. Relative accuracy of algorithm-based prescription of nasal CPAP in OSA. Resp Med 2004; 98: 152-4. [Crossref]

13. Lankford A, Proctor C, Richard R. Continuous positive airway pressure changes in bariatric surgery patients undergoing rapid weight loss. Obes Surg 2005; 15: 336-41. [Crossref]

14. Pahkala R, Seppä J, Ikonen A, Smirnov G, Tuomilehto H. The impact of pharyngeal fat tissue on the pathogenesis of obstructive sleep apnea. Sleep Breath 2014; 18: 275-82. [Crossref]

15. Gaudette E, Kimoff RJ. Pathophysiology of OSA. Eur Respir Monogr 2010; 50: 31-50. [Crossref]

16. Schwab RJ, Remmers JE, Kuna ST. Anatomy and physiology of upper airway obstruction. Kryger MH, Roth T, Dement WC editors. Principles and practice of sleep medicine, 5th edition. Missouri: Elsevier Saunders, 2011.p.1153-71. [Crossref]

17. Eckert DJ, Malhotra A. Pathophysiology of adult obstructive sleep apnea. Proc Am Thorac Soc 2008; 5: 144-53. [Crossref] 